\title{
Non-HDL Cholesterol Versus LDL Cholesterol as a CVD Risk Factor in Diabetic Subjects
}

\author{
M SAIEDULLAH ${ }^{\mathrm{a}}$, S BEGUM ${ }^{\mathrm{b}}$, S HAYAT ${ }^{\mathrm{c}}$, SM KAMALUDDIN ${ }^{\mathrm{d}}$, MR RAHMAN ${ }^{\mathrm{e}}$, MAH KHAN ${ }^{\mathrm{f}}$
}

Summary:

Objective: Serum low density lipoprotein (LDL) cholesterol is considered as the primary target of lipid lowering therapy and non-high density lipoprotein (HDL) cholesterol is the recommended second target. Recent studies claimed that non-HDL cholesterol is a better predictor of cardiovascular diseases (CVD) than LDL cholesterol. In this study we aimed to compare non-HDL cholesterol and LDL cholesterol as a CVD risk factor in confirmed diabetic subjects.

Materials and methods: In this cross-sectional observational study, 1042 confirmed diabetic subjects selected randomly were included. $\mathrm{HbA}_{1 \mathrm{c}}$ concentrations were measured by modified high-performance liquid chromatography. Serum total cholesterol (TC) and triglycerides (TG) concentrations were measured by enzymatic end point method. Serum HDL cholesterol was measured by a direct automated method and LDL cholesterol was calculated by Friedewald's formula. Subjects having TC d" $150 \mathrm{mg} / \mathrm{dL}$ and TG $>400$ $\mathrm{mg} / \mathrm{dL}$ were excluded. Selected subjects were divided into 5 groups depending on TG values (up to TG concentrations of $150 \mathrm{mg} / \mathrm{dL}, 151-200 \mathrm{mg} / \mathrm{dL}, 201-250 \mathrm{mg} / \mathrm{dL}, 251-300$ $\mathrm{mg} / \mathrm{dL}$ and 301-400 $\mathrm{mg} / \mathrm{dL}$ respectively). In each group, number of individuals with LDL cholesterol d" $100 \mathrm{mg} / \mathrm{dL}$, non HDL cholesterol d"130 mg/dL and LDL cholesterol $>100 \mathrm{mg} / \mathrm{dL}$, non-HDL cholesterol $>130 \mathrm{mg} / \mathrm{dL}$ were calculated and compared by Fisher's exact test.
Results: In the total subjects, 767 (74\%) subjects had LDL cholesterol $>100 \mathrm{mg} / \mathrm{dL}$ and 822 (79\%) subjects had nonHDL cholesterol $>130 \mathrm{mg} / \mathrm{dL}$. HbA $A_{1 c}$ values were different $(\mathrm{p}<0.02)$ in five groups and showed upward trend $(\mathrm{p}<0.01)$. All the lipid parameters studied were significantly different in five groups $(\mathrm{p}<0.0001)$ and TC, TG and non-HDL cholesterol showed upward trend ( $\mathbf{p}<0.0001)$, but HDL cholesterol and LDL cholesterol showed downward trend $(\mathrm{p}<0.0001)$. Odds ratio (OR) of likelihood of risk individuals regarding non-HDL cholesterol compared to $\mathrm{LDL}$ cholesterol were 0.50 $(\mathrm{p}<0.001), 1.32(\mathrm{p}>0.05), 2.96(\mathrm{p}<0.001), 6.49(\mathrm{p}<0.001)$ and $9.37(\mathrm{p}<0.001)$ for TG concentrations of up to 150 $\mathrm{mg} / \mathrm{dL}, 151-200 \mathrm{mg} / \mathrm{dL}, 201-250 \mathrm{mg} / \mathrm{dL}, 251-300 \mathrm{mg} / \mathrm{dL}$ and $301-400 \mathrm{mg} / \mathrm{dL}$ respectively with relative risk of 0.60 , 1.24, 2.43, 4.83, 5.10.

Conclusion: LDL cholesterol is a better tool for the detection of high-risk individuals than non-HDL cholesterol at TG concentration up to $150 \mathrm{mg} / \mathrm{dL}$, whereas non-HDL cholesterol is better than LDL cholesterol at TG concentration above $200 \mathrm{mg} / \mathrm{dL}$ as a CVD risk factor.

Key words: CVD risk factors, Non-HDL cholesterol, LDL cholesterol, Diabetes mellitus

(J Banagladesh Coll Phys Surg 2013; 31: 199-203)

a. Muhammad Saiedullah, M Sc, M Phil, Senior Lecturer, Department of Applied Laboratory Sciences, Bangladesh University of Health Sciences (BUHS), Dhaka, Bangladesh; Senior Scientific Officer, Department of Clinical Biochemistry, Bangladesh Institute of Health Sciences (BIHS), Dhaka, Bangladesh.

b. Shahnaj Begum, M Sc, Lecturer, Department of Applied Laboratory Sciences, Bangladesh University of Health Sciences (BUHS), Dhaka, Bangladesh; Senior Scientific Officer, Department of Clinical Biochemistry, Bangladesh Institute of Health Sciences (BIHS), Dhaka, Bangladesh.

c. Shoma Hayat, M Sc, Lecturer, Department of Applied Laboratory Sciences, Bangladesh University of Health Sciences (BUHS), Dhaka, Bangladesh; Scientific Officer, Department of Clinical Biochemistry, Bangladesh Institute of Health Sciences (BIHS), Dhaka, Bangladesh.

d. Syed Muhammad Kamaluddin, M Sc, Lecturer, Department of Applied Laboratory Sciences, Bangladesh University of Health Sciences (BUHS), Dhaka, Bangladesh; Senior Scientific Officer, Department of Clinical Biochemistry, Bangladesh Institute of Health Sciences (BIHS), Dhaka, Bangladesh.

e. Dr. Muhammad Rezwanur Rahman, MBBS, MD (Clinical Biochemistry), Associate Professor, Dept. of Biochemistry, Delta Medical College, Dhaka, Bangladesh.

f. Dr. Md. Aminul Haque Khan, MBBS, MCPS, FCGP, FCPS, MD [BSMMU], Professor, Department of Biochemistry, Enam Medical College, Dhaka, Bangladesh.

Address of Correspondence: Muhammad Saiedullah, M Sc, M Phil, Senior Lecturer, Department of Applied Laboratory Sciences, Bangladesh University of Health Sciences (BUHS), Mirpur, Dhaka, Bangladesh; email: md.saiedullah@gmail.com

Received: 14 March, 2013

Accepted: 10 September, 2013 


\section{Introduction:}

Non-high density lipoprotein (HDL) cholesterol is defined as the difference between total cholesterol (TC) and HDL cholesterol. Non-HDL cholesterol contains all cholesterol in lipoprotein particles considered to be atherogenic, that is low-density lipoprotein (LDL), lipoprotein(a), intermediate-density lipoprotein (IDL), and very low density lipoprotein (VLDL), chylomicron remnants, small dense LDL. Traditionally, elevated LDL cholesterol is considered as the most potent risk factor for cardiovascular diseases (CVD), but recent epidemiologic study, ${ }^{1}$ The Strong Heart population based Study in American Indians, ${ }^{2}$ longitudinal study ${ }^{3}$ and meta-analysis ${ }^{\mathbf{4 - 6}}$ showed that non-HDL cholesterol is a stronger predictor of CVD than LDL cholesterol. Comparison of cardiovascular risk markers between control and diabetic and hypertensive subjects showed that non-HDL cholesterol was higher in diseased group than in control group, LDL cholesterol showed no significant difference between diseased and control groups. ${ }^{7}$ According to the recommendation of ATPIII, ${ }^{\mathbf{8}}$ non-HDL cholesterol is the second target of lipid lowering therapy in subjects with hypertriglyceridemia and target of non-HDL cholesterol is $30 \mathrm{mg} / \mathrm{dL}$ higher for all risk groups than LDL cholesterol. ${ }^{\mathbf{8}}$ The National Cholesterol Education Panel (NCEP), ${ }^{8}$ the American Diabetes Association (ADA) ${ }^{\mathbf{9}}$ and the American College of Cardiology (ACC) Foundation ${ }^{\mathbf{1 0}}$ recommended to reduce LDL cholesterol to a goal of $<100 \mathrm{mg} / \mathrm{dL}$ and non-HDL cholesterol to a goal of $<130 \mathrm{mg} / \mathrm{dL}$. In this study we aimed to compare non-HDL cholesterol and LDL cholesterol risk for CVD in Bangladeshi diabetic subjects.

\section{Materials and methods:}

This cross-sectional observational study was conducted in the department of Clinical Biochemistry, Bangladesh Institute of Health Sciences (BIHS), Dhaka, Bangladesh. One thousand and forty two specimens obtained during April 2010 to August 2010 from confirmed diabetic subjects (both treated and untreated for the management diabetes mellitus or dyslipidemia) were analyzed. For lipid profile measurement blood specimens were collected after 10 to 12 hours fast and serum was collected after centrifugation. For $\mathrm{HbA}_{1 \mathrm{c}}$ measurement blood specimens were collected in blood collection tubes (BD Vacutainer ${ }^{\circledR}$ containing $3.6 \mathrm{mg} \mathrm{K}_{2}$ EDTA; BD, Franklin Lakes, NJ USA). All biochemical analyses were performed on same day. $\mathrm{HbA}_{1 \mathrm{c}}$ was measured by modified cation-exchange high performance liquid chromatography (HPLC) using D-10 ${ }^{\mathrm{TM}}$ glycosylated hemoglobin testing system (Bio-Rad Laboratories, Inc., Hercules, CA, 94547, USA). Serum TC and TG were measured by enzymatic end point method by Dimension RxL Max automated chemistry analyzer (Siemens Healthcare Diagnostics Ltd. USA), HDL cholesterol was measured by direct automated method using Dimension RxL Max analyzer. LDL cholesterol was calculated by Friedewald's formula ${ }^{11}$ and non-HDL cholesterol was calculated as, non-HDL cholesterol = Total cholesterol - HDL cholesterol. Subjects having TC d"150 mg/dL and TG $>400 \mathrm{mg} / \mathrm{dL}$ were excluded. Study subjects were divided into 5 groups depending on TG values. In each group, number of individuals with LDL cholesterol d" $100 \mathrm{mg} / \mathrm{dL}$, non-HDL cholesterol d"130 mg/dL and LDL cholesterol $>100 \mathrm{mg} / \mathrm{dL}$, non-HDL cholesterol $>130$ mg/dL were calculated and compared by Fisher's exact test. Data analyses were performed using GraphPad Prism version 5.03 for Windows, GraphPad Software, San Diego California USA.

\section{Results:}

Of the total subjects, $48 \%$ were male and $52 \%$ were female. The mean \pm SD of age of the total study subjects was $49.8 \pm 11.5$ years. Demographic characteristics, mean $\pm \mathrm{SD}$ of $\mathrm{HbA}_{1 \mathrm{c}}$, lipid parameters and results of statistical analyses of different groups are shown in Table I. $\mathrm{HbA}_{1 \mathrm{c}}$ values were different $(p<0.02)$ in five groups and showed upward trend $(p<0.01)$. Nineteen percent (19\%) subjects had LDL cholesterol d” $100 \mathrm{mg} / \mathrm{dL}$ and 81\% had LDL cholesterol > 100 mg/dL; 32\% had nonHDL cholesterol d" $130 \mathrm{mg} / \mathrm{dL}$ and 68\% had non-HDL cholesterol $>130 \mathrm{mg} / \mathrm{dL}$ in Group I. Number of nonHDL cholesterol classified risk individuals were significantly lower than LDL cholesterol classified risk individuals in Group I (OR: 0.50, 95\% CI: 0.37-0.69, $p<0.001)$. Twenty six percent $(26 \%)$ individuals had LDL cholesterol $\leq 100 \mathrm{mg} / \mathrm{dL}, 74 \%$ had LDL cholesterol $>100 \mathrm{mg} / \mathrm{dL}$ and 21\% individuals had non-HDL cholesterol $\leq 130 \mathrm{mg} / \mathrm{dL}, 79 \%$ had non-HDL cholesterol 
$>130 \mathrm{mg} / \mathrm{dL}$ in Group II. No statistically significant difference of the number of non-HDL cholesterol classified risk individuals and LDL cholesterol classified risk individuals was observed in Group II (OR: 1.32, 95\% CI: 0.86-2.01, $p>0.05)$. In Group III, 27\% individuals had LDL cholesterol d" $100 \mathrm{mg} / \mathrm{dL}, 73 \%$ had LDL cholesterol $>100 \mathrm{mg} / \mathrm{dL}$ and $11 \%$ individuals had non-HDL cholesterol d" 130 mg/dL, 89\% had nonHDL cholesterol > $130 \mathrm{mg} / \mathrm{dL}$. Number of non-HDL cholesterol classified risk individuals were significantly higher than LDL cholesterol classified risk individuals in Group III (OR: 2.96, 95\% CI: 1.70-5.16, $p<0.001$ ). In group IV, 30\% individuals had LDL cholesterol $\leq$ $100 \mathrm{mg} / \mathrm{dL}, 70 \%$ had LDL cholesterol $>100 \mathrm{mg} / \mathrm{dL}$ and $7 \%$ individuals had non-HDL cholesterol $\leq 130 \mathrm{mg} /$ $\mathrm{dL}, 93 \%$ had non-HDL cholesterol $>130 \mathrm{mg} / \mathrm{dL}$. Number of non-HDL cholesterol classified risk individuals were significantly higher than LDL cholesterol classified risk individuals in Group IV (OR: 6.49, 95\% CI: 2.55-16.53, $p<0.001)$. In Group V, 51\% individuals had LDL cholesterol $\leq 100 \mathrm{mg} / \mathrm{dL}, 49 \%$ had LDL cholesterol $>100 \mathrm{mg} / \mathrm{dL}$ and $10 \%$ individuals had non-HDL cholesterol $\leq 130 \mathrm{mg} / \mathrm{dL}, 90 \%$ had non-HDL cholesterol $>130 \mathrm{mg} / \mathrm{dL}$. Number of non-HDL cholesterol classified risk individuals was significantly higher than LDL cholesterol classified risk individuals in Group V (OR: 9.37, 95\% CI: 4.37-20.07, $p<0.001$ ). The relative risk of residual risk individuals regarding non-HDL cholesterol compared to LDL cholesterol were $0.6,1.24,2.43,4.83$ and 5.10 in different groups respectively (Table-I).

Trend line of lipid parameters with incremental TG groups is shown in Fig. 1. The trends for TC, TG and non-HDL cholesterol were upward $(p<0.0001)$ and that for HDL cholesterol and LDL cholesterol were downward $(p<0.0001)$.

Table-I

\begin{tabular}{|c|c|c|c|c|c|}
\hline \multicolumn{6}{|c|}{$\begin{array}{c}\text { Demographic characteristics, mean } \pm S D \text { of biochemical parameters and } \\
\text { statistical analyses of different groups }\end{array}$} \\
\hline & $\begin{array}{c}\text { Group I } \\
\text { TG: } \leq 150 \\
\text { (mg/dL) }\end{array}$ & $\begin{array}{c}\text { Group II } \\
\text { TG: } 151-200 \\
\text { (mg/dL) }\end{array}$ & $\begin{array}{c}\text { Group III } \\
\text { TG: 201-250 } \\
\text { (mg/dL) }\end{array}$ & $\begin{array}{c}\text { Group IV } \\
\text { TG: 251-300 } \\
\text { (mg/dL) }\end{array}$ & $\begin{array}{c}\text { Group V } \\
\text { TG: >300 } \\
\text { (mg/dL) } \\
\end{array}$ \\
\hline Age (Years) & $50.23 \pm 11.15$ & $50.73 \pm 11.89$ & $49.12 \pm 11.78$ & $48.59 \pm 11.93$ & $48.22 \pm 11.16$ \\
\hline $\operatorname{Sex}(M / F) \%$ & $45 / 55$ & $42 / 58$ & $54 / 46$ & $57 / 43$ & $49 / 51$ \\
\hline No. of Subjects & 414 & 244 & 188 & 96 & 100 \\
\hline $\mathrm{HbA}_{1 \mathrm{c}} \%$ & $9.02 \pm 2.41$ & $9.23 \pm 2.41$ & $9.53 \pm 2.53$ & $9.73 \pm 2.51$ & $9.61 \pm 2.47$ \\
\hline TC (mg/dL) & $190.3 \pm 29.7$ & $199.7 \pm 33.9$ & $205.2 \pm 35.1$ & $210.0 \pm 36.4$ & $212.1 \pm 43.0$ \\
\hline TG (mg/dL) & $115.4 \pm 22.5$ & $174.3 \pm 14.1$ & $221.5 \pm 15.0$ & $272.8 \pm 14.5$ & $344.0 \pm 28.9$ \\
\hline HDLC (mg/dL) & $41.97 \pm 8.19$ & $39.86 \pm 8.02$ & $37.34 \pm 7.95$ & $36.82 \pm 7.16$ & $35.68 \pm 7.70$ \\
\hline LDLC (mg/dL) & $125.01 \pm 28.20$ & $125.03 \pm 32.63$ & $122.61 \pm 32.78$ & $119.03 \pm 32.83$ & $108.42 \pm 39.71$ \\
\hline Non-HDLC (mg/dL) & $148.4 \pm 28.92$ & $159.87 \pm 32.84$ & $167.86 \pm 31.93$ & $173.20 \pm 32.66$ & $176.46 \pm 39.60$ \\
\hline OR & $0.50^{* * *}$ & $1.32^{\mathrm{NS}}$ & $2.96 * * *$ & $6.49 * * *$ & $9.37 * * *$ \\
\hline $95 \%$ CI & $0.37-0.69$ & $0.86-2.01$ & $1.70-5.16$ & $2.55-16.53$ & 4.37-20.07 \\
\hline Relative Risk & 0.60 & 1.24 & 2.43 & 4.83 & 5.10 \\
\hline
\end{tabular}

***, $p<0.001$; NS, Not significant 


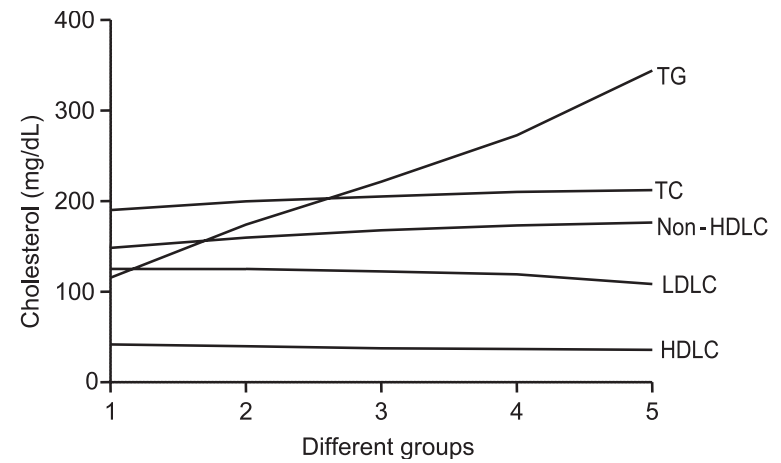

Fig.-1: Trends of lipid parameters with the increase of serum TG

\section{Discussion:}

With the increment of serum TG, the odds ratio of nonHDL cholesterol risk individuals compared to LDL cholesterol risk individuals increased from 0.5 to 9.37 (Table-I). Since odds ratio was $0.5(p<0.001)$ at TG concentration d" $150 \mathrm{mg} / \mathrm{dL}$, LDL cholesterol showed better performance than non-HDL cholesterol to evaluate risk factor more accurately. At serum TG concentrations of 151-200 mg/dL, or was not statistically significant $(p>0.05)$, LDL cholesterol or non-HDL cholesterol can be used to include residual risk individuals but relative risk was 1.24 to exclude residual risk individual for LDL cholesterol. At serum TG $>200$ $\mathrm{mg} / \mathrm{dL}$, ors were stronger and statistically highly significant $(p<0.001)$, so that non-HDL cholesterol classified risk individuals more accurately than LDL cholesterol. It was also evident from Fig. 1 that, with the increase of TG, TC and decrease of serum HDL cholesterol, serum LDL cholesterol decreases which misleads the risk individuals whereas non-HDL cholesterol increases with the increase of TC, TG and with the decrease of HDL cholesterol.

In hypertriglyceridemic subjects, LDL cholesterol targeted therapy may mask the non-HDL cholesterol risk. Peters ${ }^{12}$ described a diabetic subject whose TC concentration was $207 \mathrm{mg} / \mathrm{dL}$, triglycerides was $364 \mathrm{mg} /$ $\mathrm{dL}$, HDL cholesterol was $36 \mathrm{mg} / \mathrm{dL}$, LDL cholesterol was $98 \mathrm{mg} / \mathrm{dL}$ (<optimum level) and non-HDL cholesterol was $171 \mathrm{mg} / \mathrm{dL}$ (>130 mg/dL). Since his LDL cholesterol level was at goals, no steps were taken to reduce non-HDL cholesterol. Several years later unfortunately the patient was found to have severe CAD and required coronary artery bypass grafting. ${ }^{12}$
Since non-HDL contains all the atherogenic cholesterol, is highly correlated with more atherogenic apolipoprotein $\mathrm{B},{ }^{13,14}$ effective to include residual high risk subjects and associated with an increased risk of cardiac death, ${ }^{15}$ it would be the better target of classification of lipid risk individuals and lipid lowering therapy at TG concentration greater than $200 \mathrm{mg} / \mathrm{dL}$.

\section{Conclusion:}

LDL cholesterol classified high-risk subjects better than non-HDL cholesterol at TG concentration up to $150 \mathrm{mg} /$ dL. No significant difference is observed for LDL cholesterol and non-HDL cholesterol CVD risk classification at TG concentration of $151-200 \mathrm{mg} / \mathrm{dL}$ but non-HDL cholesterol classified high-risk subjects better than LDL cholesterol at TG concentration above $200 \mathrm{mg} / \mathrm{dL}$ for CVD risk.

\section{References:}

1. Cui Y, Blumenthal RS, Flaws JA, Whiteman MK, Langenberg P, Bachorik PS, et al. Non-high-density lipoprotein cholesterol level as a predictor of cardiovascular disease mortality. Arch Intern Med 2001;161:1413-19.

2. Lu W, Resnick HE, Jablonski KA, Jones KL, Jain AK, Howard WJ, et al. Non-HDL cholesterol as a predictor of cardiovascular disease in type 2 diabetes. The Strong Heart Study. Diabetes Care 2003;26:16-23.

3. Liu J, Sempos C, Donahue RP, Dorn J, Trevisan M, Grundy SM. Joint distribution of non-HDL and LDL cholesterol and coronary heart disease risk prediction among individuals with and without diabetes. Diabetes Care 2005;28:1916-21.

4. Robinson JG, Wang S, Smith BJ, Jacobson TA. Meta-analysis of the relationship between non-high-density lipoprotein cholesterol reduction and coronary heart disease risk. J Am Coll Cardiol 2009;53:316-22.

5. Boekholdt SM, Arsenault BJ, Mora S, Pedersen TR, LaRosa JC, Nestel PJ, et al. Association of LDL cholesterol, non-HDL cholesterol, and apolipoprotein B levels with risk of cardiovascular events among patients treated with statins: a meta-analysis. J Am Med Assoc 2012;28;307:1302-9.

6. Sniderman AD and Thanassoulis. Among statin-treated patients, LDL, non-HDL and apoB cholesterol biomarkers were associated with increased risks of cardiovascular events. Evid Based Med 2013;18:73-74.

7. Freddy C, Mary L, Jorge C, Manuel V, Joselyn R, Xavier G, et al. Determination of non-HDL cholesterol in diabetic and hypertensive patients. Am J Ther 2010;17:337-40.

8. National Cholesterol Education Panel. Third report of the National Cholesterol Education Program (NCEP) Expert Panel on Detection, Evaluation, and Treatment of High Blood Cholesterol in Adults (Adult Treatment Panel III): final report. Circulation 2002;106:3143-421. 
9. American Diabetes Association. Dyslipidemia management in adults with diabetes. Diabetes Care 2004;27(Suppl. 1): S68-S71.

10. Brunzell JD, Davidson M, Furberg CD, Goldberg RB, Howard $\mathrm{BV}$, Stein JH, et al. Lipoprotein management in patients with cardiometabolic risk: consensus conference report from the American Diabetes Association and the American College of Cardiology Foundation. J Am Coll Cardiol 2008;51:151224.

11. Friedewald WT, Levy RI, and Fredrickson DS. Estimation of the concentration of low-density lipoprotein cholesterol in plasma, without use of the preparative ultracentrifuge. Clin Chem 1972;18:499-502.

12. Peters AL. Clinical relevance of non-HDL cholesterol in patients with diabetes. Clinical Diabetes 2008;26:3-7.
13. Expert Panel on Detection, Evaluation, and Treatment of High Blood Cholesterol in Adults. Executive summary of the third report of the National Cholesterol Education Program (NCEP) Expert Panel on Detection, Evaluation, and Treatment of High Blood Cholesterol in Adults (Adult Treatment Panel III). J Am Med Assoc 2001;285:2486-97.

14. Kim BJ, Hwang ST, Sung KC, Kim BS, Kang JH, Lee MH, et al. Comparison of the relationships between serum apolipoprotein B and serum lipid distributions. Clin Chem 2005;51:2257-63.

15. Fukushima Y, Ohmura H, Mokuno H, Kajimoto K, Kasai T, Hirayama S, et al. Non-high-density lipoprotein cholesterol is a practical predictor of long-term cardiac death after coronary artery bypass grafting. Atherosclerosis 2012;221:206-11. 